\title{
OS DOMÍNIOS DA HOSPITALIDADE E A GESTÃO DE STAKEHOLDERS EM RECRUTAMENTO E SELEÇÃO ESTUDO DE CASOS MÚLTIPLOS: ESTANPLAZA, TRAVEL INN E TRANSAMÉRICA.
}

\section{RESUMO}

O presente estudo propôs analisar as relações existentes entre recrutamento e seleção e seus stakeholders, considerando os domínios da hospitalidade e suas características como fatores influentes para recrutar e selecionar novos colaboradores. A abordagem da pesquisa foi qualitativa com a metodologia voltada para o estudo de casos múltiplos, o que contribuiu para a modalidade de investigação empírica. Para essa investigação foram selecionadas três redes de hotéis por reunirem características que viabilizaram uma análise comparativa do estudo, foram utilizadas para coleta de dados, três fontes de evidências: entrevistas, observações diretas e documentação. As redes selecionadas, Estanplaza Hotels, Hotéis Transamérica e Travel Inn. O objetivo geral foi compreender se os processos utilizados em recrutamento e seleção estabelecem características dos domínios da hospitalidade. Especificamente buscou: observar a dinâmica do processo de recrutamento e seleção das redes hoteleiras; analisar o conteúdo relacionado aos domínios da hospitalidade nas ferramentas utilizadas no processo de recrutamento e seleção; e conhecer os stakeholders dessa área. A investigação foi realizada por intermédio de entrevistas com os gestores dos meios de hospedagem e com os stakeholders da área de recrutamento e seleção, baseadas em um roteiro de entrevista semiestruturado. Por intermédio desta pesquisa foi possível identificar que algumas características dos domínios da hospitalidade são considerados no processo de recrutamento e seleção. As redes hoteleiras pesquisadas, entretanto, apontam que é necessária a utilização de instrumentos e processos que viabilizem esse tipo de análise.

Palavras-chave: Hospitalidade; Gestão. Hotéis; Recrutamento e Seleção; Stakeholders.

\section{AREAS OF HOSPITALITY MANAGEMENT AND STAKEHOLDERS IN RECRUITMENT AND SELECTION MULTIPLE CASE STUDY: ESTANPLAZA, TRAVEL INN AND TRANSAMÉRICA.}

\section{ABSTRACT}

This research aims to analyze the relationships between recruitment and selection and its stakeholders, considering the areas of hospitality and its characteristics as influential factors to recruit and select new employees. The research approach was qualitative methodologies for the study of multiple cases, which contributed to the form of empirical research. For this investigation were selected by three chains together features that enabled a comparative analysis of the study, which were used for data collection, three sources of evidence: interviews, direct observations and documentation. The selected networks, Estanplaza Hotels, Hotels Transamerica and Travel Inn Hotels The overall goal was to understand the processes used in recruitment and selection set features the fields of hospitality. From this issue were established specific objectives: to observe the dynamics of recruitment and selection of chains; analyze the content related to the fields of hospitality in the tools used in the process of recruitment and selection, and meet stakeholders in this area. The research was conducted through interviews with managers of lodging facilities and with stakeholders in the area of recruitment and selection, based on a semistructured interview guide. Through this research, we found that some features of the fields of hospitality are considered in the process of recruitment and selection. Chains surveyed, however, point out that it is necessary to use tools and processes that enable this type of analysis.

Keywords: Hospitality; Management; Hotels; Recruitment and Selection; Stakeholders. 

Múltiplos: Estanplaza, Travel Inn e Transamérica.

\section{ÁREAS DE HOSPITALIDAD Y GESTIÓN DE LOS INTERESADOS EN RECLUTAMIENTO Y SELECCIÓN MÚLTIPLE ESTUDIO DE CASO: TRYP, TRAVEL INN AND TRANSAMÉRICA.}

\section{RESUMEN}

Este estudio tuvo como objetivo analizar las relaciones entre el reclutamiento y la selección y sus grupos de interés, teniendo en cuenta los campos de la hospitalidad y sus características como influyente para reclutar y seleccionar nuevos factores empleados. El enfoque de la investigación fue cualitativa y metodologías para el estudio de casos múltiples, lo que contribuyó a la forma de la investigación empírica. Para esta investigación tres cadenas fueron seleccionados por reunir características que permitieron un análisis comparativo del estudio, se utilizaron para la recolección de datos, tres fuentes de evidencia: entrevistas, observaciones directas y la documentación. Las redes seleccionadas, Tryp, Transamerica y Travel Inn. Objetivo general era comprender los procesos utilizados en el reclutamiento y selección de características establecen dominios de la hospitalidad. Específicamente buscado: observar la dinámica del proceso de reclutamiento y selección de las cadenas; para analizar los campos relacionados de la hospitalidad en las herramientas utilizadas en el contenido de los procesos de reclutamiento y selección; y conocer a los interesados en esta área. La investigación se realizó a través de entrevistas con los gestores de las instalaciones de alojamiento y con las partes interesadas en el área de reclutamiento y selección, basada en un guión de entrevista semiestructurada. A través de esta investigación, se encontró que algunas de las características de las áreas de hospitalidad se consideran en el proceso de reclutamiento y selección. Las cadenas encuestadas, sin embargo, señalan que se requiere el uso de herramientas y procesos que permiten este tipo de análisis.

Palabras-clave: Hospitalidad; Gestión; Hoteles; Reclutamiento y Selección; Las partes interesadas.

\footnotetext{
${ }^{1}$ Mestre em Hospitalidade pela Universidade Anhembi Morumbi - UAM. Gestor de Desenvolvimento em Recursos Humanos do Estanplaza Administradora Hoteleira e Comercial. Brasil. E-mail: thiagosbarai@gmail.com

${ }^{2}$ Doutora em Ciências da Comunicação pela Universidade de São Paulo - USP. Professor da Universidade Anhembi Morumbi - UAM. Brasil. E-mail: ewada@uol.com.br
} 


\section{INTRODUÇÃ̃O}

As pesquisas sobre meios de hospedagem e seus departamentos se confundem algumas vezes com os estudos sobre hospitalidade, esse fato ocorre pela proximidade nos exemplos práticos utilizados nas reflexões sobre a hospitalidade, que geralmente estão relacionados aos equipamentos de hospedagem (ALDRIGUI, 2007). A relação inversa também existe, segundo Lashley e Morrison (2004), a hospitalidade se confunde com os meios de hospedagem; os ingleses utilizam o termo hospitality como uma forma de descrever o conjunto de atividades do setor de serviços associadas à oferta de alimentos, bebidas e acomodação.

Considerando que existem três alicerces como ponto de partida para esta pesquisa, sendo o primeiro ligado às características dos domínios da hospitalidade, o segundo referente à existência de mais de um local oferecendo o mesmo tipo de serviço de acomodação e o terceiro onde há a necessidade de intermediários que possibilitem a vivência do que está sendo oferecido; é compreensível que durante os anos os meios de hospedagem se preocupem com a contratação, treinamento e retenção dos melhores colaboradores como forma de competir entre si.

Segundo Prosérpio (2007), uma das razões do crescimento da oferta de meios de hospedagem é resultado do investimento das redes internacionais nos grandes centros de negócios pós-1994, período em que a economia nacional passou a ter maior estabilidade com a abertura comercial para investimentos estrangeiros, à desregulamentação da economia e o aumento da renda da classe média.

A competitividade existente entre os meios de hospedagem independe da tipologia dos hotéis e tem como um dos seus objetivos estabelecerem uma carteira maior de clientes. Para obter esse resultado os hotéis podem tomar ações que envolvem as diversas áreas que fazem parte da sua estrutura organizacional, sejam estas medidas os descontos em tarifas, as reformas em apartamentos, reformulações nos cardápios ou ações de recrutamento e seleção.

A relação existente entre a área de recrutamento e seleção e seus stakeholders é um dos pontos de partida desta pesquisa. A gestão dos stakeholders enfatiza a importância do relacionamento entre diferentes grupos de interesse e a organização, sendo fundamental para a área compreender o seu papel e a sua responsabilidade para com os atores que interagem com a mesma (FREEMAN, 1984).

O foco em recrutamento e seleção se dá por duas razões, a primeira se justifica pela importância do controle da qualidade do serviço, segundo Guerrier (2000, p. 62) "as empresas de hospitalidade, como outras empresas de serviços, têm de controlar tanto a qualidade tangível de seu produto como a qualidade intangível do serviço"; e segunda razão é a relação do autor com a gestão de recrutamento e seleção em meios de hospedagem e a compreensão de que selecionar e recrutar colaboradores alinhados aos conceitos da hospitalidade contribui para uma percepção genuína sobre os serviços prestados por um hotel.

Para compreender a atual gestão de recrutamento e seleção, além da relação da área com seus stakeholders, a proposta desta pesquisa é observar as relações entre a área de recrutamento e seleção e a utilização dos domínios da hospitalidade como facilitador nas contratações; assim como identificar os stakeholders e compreender os impactos deles sobre a área de recrutamento seleção. Dessa forma, levantou-se a seguinte questão de investigação: Quais características dos domínios da hospitalidade os processos de recrutamento e seleção consideram no momento de seleção e contração de novos colaboradores? Propõe-se, como objetivo geral da pesquisa, compreender se os processos utilizados em recrutamento e seleção estabelecem características dos domínios da hospitalidade. Como objetivos específicos, a investigação buscou observar a dinâmica do processo de recrutamento e seleção das redes hoteleiras; analisar o conteúdo relacionado aos domínios da hospitalidade nas ferramentas utilizadas no processo de recrutamento e seleção; e conhecer os stakeholders dessa área.

A partir das investigações preliminares, foram estabelecidos os seguintes pressupostos: os processos de recrutamento consideram as características dos domínios da hospitalidade; as etapas de seleção consideram as características dos domínios da hospitalidade no momento da avaliação dos candidatos; e a área de recrutamento e seleção não considera que existam impactos das contratações nos stakeholders das redes hoteleiras.

Para contextualizar a questão e cumprir os objetivos propostos, tanto o geral quanto os específicos, este artigo foi estruturado em três sessões, o primeiro trata dos conceitos de domínios da hospitalidade e serviços hoteleiros, o segundo aborda os stakeholders e recrutamento e seleção, e o terceiro apresenta o estudo de casos múltiplos a partir da caracterização, descrição, discussão e análise comparativa dos estudos.

\section{METODOLOGIA}

Para elaborar o modelo conceitual e operativo da pesquisa, tomou-se como apoio a visão baseada nos stakeholders, realizou-se uma pesquisa bibliográfica de caráter exploratório, permitindo uma maior compreensão em torno do tema. Em seguida, fez-se um levantamento bibliográfico, utilizando periódicos 

Múltiplos: Estanplaza, Travel Inn e Transamérica.

nacionais e internacionais, livros, estudos e pesquisas desenvolvidas por empresas de análise de mercado, internet e pesquisas acadêmicas com temas ligados aos meios de hospedagem, stakeholders, serviços e recrutamento e seleção.

Por se tratar de uma pesquisa fundamentada em fatos empíricos e descrever uma situação existente, optou-se pelo estudo de casos múltiplos, que de acordo com Yin (2010) é uma investigação empírica que investiga um fenômeno contemporâneo dentro de seu contexto da vida real. Optou-se por um estudo de casos múltiplos de caráter exploratório, segundo Dencker e Da Viá (2001, p. 59) “um estudo exploratório aumenta a familiaridade do pesquisador com o fenômeno ou com o ambiente que pretende investigar".

A primeira etapa do estudo contemplou a pesquisa bibliográfica, onde se realizou a revisão de literatura para domínios da hospitalidade, segmento hoteleiro, stakeholders e recrutamento e seleção.

$\mathrm{Na}$ segunda etapa, a pesquisa foi realizada de acordo com o protocolo de estudo de casos múltiplos, proposto por Yin (2010, p. 93) é uma investigação empírica que investiga um fenômeno contemporâneo dentro de seu contexto da vida real. Para o procedimento de campo, por abranger o estudo dos stakeholders, a pesquisa buscou compreender a influência desses stakeholders na área de recrutamento e seleção das redes hoteleiras, a pesquisa investigou três grupos distintos, (1) os responsáveis pelas áreas de operação ou recursos humanos, definidores das estratégias de recrutamento e seleção, (2) os responsáveis por recrutamento e seleção, executores dessas estratégias de recrutamento e seleção, (3) os responsáveis por empreendimentos, executores dessas estratégias de recrutamento e seleção e receptores finais dos candidatos. $\mathrm{O}$ acesso a estes grupos de entrevistados se deu por amostragem autogerada, as entrevistas foram aplicadas pessoalmente no ambiente de trabalho de cada um dos indivíduos participantes da amostra. Tratando-se de uma amostragem autogerada, os indivíduos que formaram o primeiro grupo de entrevistados contribuíram para a indicação (e a geração da amostra) dos indivíduos do segundo grupo e estes ajudaram a formar o terceiro.

As redes escolhidas como objeto de estudo nesta pesquisa, Estanplaza Hotels, Hotéis Transamérica e Travel Inn Hotéis, foram selecionadas por se tratarem de organizações nacionais, com empreendimentos na cidade de São Paulo, focadas no mesmo segmento (business) e por gerenciarem meios de hospedagem com o mesmo conceito (condo-hotel) ${ }^{3}$. Outro fator que deve ser destacado foi a conveniência de selecionar

3 O condo-hotel é um empreendimento imobiliário constituído sob a forma de condomínio, composto por apartamentos destinados exclusivamente à hospedagem, ou seja, não podem ser utilizados como residência permanente (Sansiviero e Dias, 2005) redes hoteleiras onde o autor possui fácil acesso as informações. Somadas elas gerenciam 61 empreendimentos, dentro e fora do país, 9.795 unidades habitacionais, empregam 3.926 colaboradores e uma ocupação média entre $51 \%$ e $70 \%$.

A utilização de redes hoteleiras com o mesmo perfil contribuem para uma melhor análise dos seus stakeholders, segundo Oliveira e Wada (2012):

“... desde a concepção de um apart-hotel, até o seu funcionamento, há participação de diversos grupos de influência" assim quando o empreendimento se instala, inúmeros grupos têm seus interesses afetados de forma positiva ou negativa, causando repercussões sobre a organização a curto, médio e longo prazo. (Oliveira; Wada, 2012, p. 14)8.

As entrevistas semiestruturadas direcionadas aos principais dirigentes de cada organização, com roteiros pré definidos trataram de questões como: nome, formação acadêmica, função na empresa, tempo na função, principais atribuições; Dados da rede hoteleira e/ou hotel: nome da rede, número hotéis no Brasil, número de hotéis em São Paulo, números de apartamentos, números de funcionários, ocupação médio, outros índices que o entrevistado considere importante; Identificação dos stakeholders da área de recrutamento e seleção: identificação espontânea de quatro grupos de stakeholders, justificativa da escolha, apresentação do mapa conceitual dos stakeholders, classificação de 11 grupos segundo sua relevância, levantamento das estratégias de gestão com esses stakeholders; Identificação da área Recrutamento e Seleção: reconhecimento da área de recrutamento e seleção (centralizado ou por hotel), identificação dos meios de divulgação das vagas, das etapas para seleção de candidatos e das ferramentas para avaliação dos candidatos; Caracterização dos domínios da hospitalidade: apresentação do mapa conceitual dos domínios da hospitalidade, identificação das áreas dentro dos domínios, identificação das características dos domínios, levantamento da correlação entre as características e as ferramentas de avaliação dos candidatos.

As entrevistas tiveram duração média de 40 minutos, algumas se prolongaram por mais tempo, de acordo com a disponibilidade do entrevistado. Para a seleção dos entrevistados considerara-se o grau de conhecimento e representatividade que eles exercem na organização escolhida para o estudo, os intuitos foram buscar uma visão mais ampla das estratégias praticadas pela empresa e assegurar maior veracidade das informações. Os três entrevistados selecionados foram: Abel Feris, Superintendente Operacional da rede Estanplaza Hotels; Vera Lucia Lopes Castro, Gerente de Recursos Humanos da rede Hotéis Transamérica; Rianne Vasconcellos, Gerente Geral na Travel Inn 
Hotéis e representante do grupo no comitê de Recursos Humanos do $\mathrm{FOHB}^{4}$.

Ao finalizar as entrevistas com os representantes das organizações, foi solicitada a possibilidade de se realizar uma segunda etapa de entrevistas aos representantes de outros dois grupos considerados mais relevantes pelo entrevistado. A finalidade dessa segunda etapa foi de evitar uma visão unilateral do estudo e ouvir outros interlocutores que afetam ou são afetados pela realização dos objetivos da organização. Assim, foram indicados: Fabiano Orso, Gerente de Recrutamento e Seleção da rede Estanplaza Hotels, Marco Aurélio, Gerente Geral na Estanplaza Hotels, Flavia Ferreira da Silva, Coordenadora de Recrutamento e Seleção da rede Hotéis Transamérica, Charles Giudici, Gerente Geral Operacional na rede hotéis Transamérica, Nathia Cavallaro de Andrade, Diretora de Desenvolvimento na MAAT e Barbara Dvorzak, Gerente Geral na Travel Inn Hotéis.

A segunda fonte de evidências foi à observação direta para identificar possíveis divergências com as entrevistas. A observação foi realizada de forma espontânea aos fatos que ocorrem no ambiente, inclusive durante a visita de campo, como nos dias das entrevistas. $\mathrm{O}$ foco principal foi à observação da relação existente entre os grupos envolvidos, visando melhor compreensão da relação entre as áreas de recrutamento e seleção e seus stakeholders, além da observação da utilização de ferramentas que considerem as características dos domínios da hospitalidade. A terceira fonte de evidências foram os documentos disponibilizados pelos entrevistados para corroborar tanto com os dados das entrevistas como com os das observações. Para esta coleta de dados foram utilizadas fontes secundárias, isto é, das organizações hoteleiras, tais como press releases, textos publicitários, artigos de jornais, revisão bibliográfica e outros documentos pertinentes à investigação.

$\mathrm{Na}$ análise dos dados, todas as fontes de evidências foram analisadas, por meio do cruzamento das informações obtidas, para evidenciar as semelhanças e diferenças de cada organização. Yin (2010, p. 158) diz: "todos os estudos de pesquisa empírica, inclusive os estudos de caso, têm uma história para contar. A história difere da narrativa ficcional porque engloba seus dados, mas permanece uma história, porque pode ter princípio, meio e fim". Cabe ao pesquisador, à orientação suficiente para criar sua história e escolher a melhor estratégia analítica que respeite as prioridades, o que analisar e por que analisar.

\section{DOMÍNIOS DA HOSPITALIDADE E O SERVIÇOS HOTELEIRO}

As características dos domínios das atividades da hospitalidade aplicadas nesse estudo foram extraídas do diagrama apresentado por Lashley e Morrison (2004), onde eles permitem visualizar os três domínios da hospitalidade, privado, social e comercial. Cada domínio representa um aspecto da oferta e cada oferta possui características de atratividade que serão propostas na pesquisa.

\footnotetext{
${ }^{4}$ FOHB - Fórum de Operadores Hoteleiros do Brasil
} 

Múltiplos: Estanplaza, Travel Inn e Transamérica.

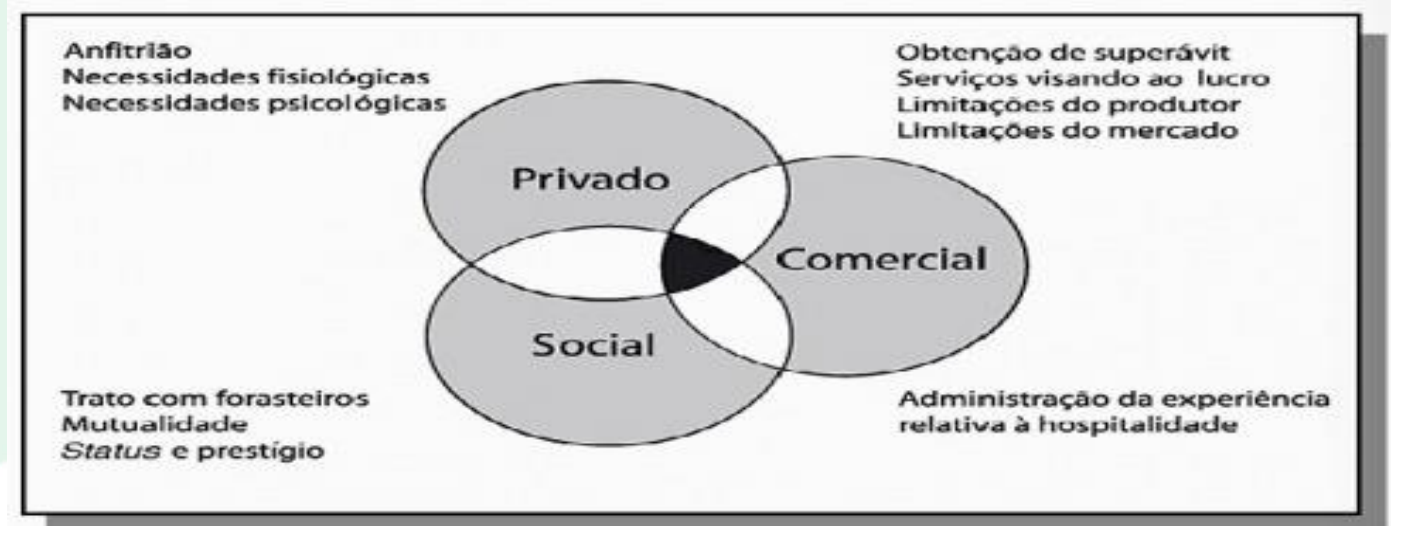

Figura 1 - Atividades relacionadas com a hospitalidade Fonte: Lashley e Morrison, p. 6

Segundo Lashley e Morrison (2004)

(...) cada domínio representa um aspecto da oferta da hospitalidade, que é tanto independente como sobreposto. O domínio social da hospitalidade considera os cenários sociais em que a hospitalidade e os atos ligados à condição de hospitalidade ocorrem junto com os impactos de forças sociais sobre a produção e consumo de alimentos, bebidas e acomodação. O domínio privado considera o âmbito das questões associadas à oferta da "trindade" 5 no lar, assim como leva em consideração o impacto do relacionamento entre anfitrião e hóspede. $\mathrm{O}$ domínio comercial diz respeito à oferta de hospitalidade enquanto atividade econômica e inclui as atividades dos setores tanto privados quanto público. (Lashley e Morrison, 2004, p.5).

Para compreender a hospitalidade no domínio social, Lashley e Morrison (2004), sugerem que é necessário analisar o contexto social em que as atividades deste domínio ocorrem. Segundo Quadros (2011), o domínio social da hospitalidade pode ser representado pelo "conjunto de comportamentos da vida privada, exercida dentro de um limitado círculo de amizade ou relacionamento, ou seja, nasce no contexto da vida familiar e se expande para as outras esferas das relações humanas" (QUADROS, 2011, p. 43-57)

A hospitalidade no domínio privado, de acordo com Lashley e Morrison (2004), é representada pela oferta de alimentos, bebidas e acomodação, esses ofertas representam atos de amizade que instituem laços simbólicos e vínculos entre as pessoas envolvidas no processo.

Ainda sobre o domínio privado, Telfer (1996), estabelece que ser um bom anfitrião implica mais do

5 Oferta de alimentos, bebidas e acomodação (Lashley e Morrison, 2004) que determinadas condutas, como garantir que há bebida suficiente e que os hóspedes têm o bastante para comer; para ser um bom anfitrião é necessário ter um desejo genuíno de agradá-los e deixá-los satisfeitos.

A hotelaria em si é discutida no âmbito comercial, mas a "é muito importante observar que a Hospitalidade Comercial por si não resultará em serviços completos de hospitalidade." (Wada, 2007, p. 10). De acordo com a mesma a sobreposição dos três domínios para o profissional de hotelaria é necessário para "alcançar posições de gestão, caso contrário, estará apenas operacionalizando parte do processo." (Wada, 2007, p. 11).

Para Wada (2007)

Ao observar um hotel em funcionamento, nota-se que há atividades onde as características do domínio privado são essenciais, tais como todos os serviços operacionais de back of the house camareiras, funcionários da manutenção, da cozinha, de segurança; há outras que realçam o domínio social, em especial no front of the house - recepcionistas, porteiros, mensageiros, maîtres, garçons, coordenadores de eventos, monitores de recreação, equipes comerciais; aqueles que, dentre suas tarefas habituais têm a prioridade no domínio comercial estão em áreas de controladoria, compras, auditoria. Áreas de assessoria ou de apoio à operação como recursos humanos, marketing, jurídico, implantações e mesmo a gerência geral se sentem divididos em atender às diversas demandas, muitas vezes sem perceber que estão lidando com domínios diferentes de hospitalidade. (WADA, 2007, p. 12).

Considerando então os três domínios da hospitalidade, faz-se necessário propor características a cada um deles, dessa forma foram reunidos os pontos de vista de Lashley e Morrison (2004) e Wada (2007) para estabelecer um modelo. 
Assim como Lashley e Morrison (2004) que consideram a hospitalidade como uma troca comercial e mercadológica que acontece entre o receptor (hóspede) e o fornecedor (anfitrião) da hospitalidade, Silveira (2005) aponta que a hotelaria pode "ser compreendida como uma espécie de profissionalização dos ritos e da estrutura da Hospitalidade, transformando o ato de hospedar em mercadoria". (Silveira, 2005, p. 129).

Segundo Beni (2001):

O hotel é uma empresa de prestação de serviços e diferencia-se completamente de outros estabelecimentos industriais e comerciais. Enquanto na indústria pode-se planejar o número de equipamentos, instalações e pessoal para um determinado tipo de produção, o mesmo não acontece com a hotelaria, que fica no aguardo dos clientes para pôr em funcionamento seu esquema operacional. O produto hoteleiro é estático. $\mathrm{O}$ consumidor deve ir até ele. Já as empresas industriais ou comerciais fazem chegar o produto até o cliente. (BENI, 2001, 195)

O Banco Nacional do Desenvolvimento (2000), também estabelece o hotel como um prestador de serviço, com fornecimento de hospedagem, segurança, alimentação e demais serviços inerentes ao bem receber, assim dispõe, atualmente, não só de hospedagem e cama da manhã, mas diversos serviços que agregam valor, tais como, restaurantes, roomservice, eventos, spas, dentre outros. Estes serviços possibilitam que o hóspede passe mais tempo no empreendimento e usufrua de diversos serviços em um mesmo ambiente.

De acordo com a Organização Mundial do Turismo (2013) é importante observar o atual momento da demanda de receptores por intermédio de indicadores do turismo que atualmente é um setor expressivo para economia mundial, o segmento representa 9\% do Produto Interno Bruto mundial, além disto, são 235 milhões de pessoas exercendo funções relacionadas ao turismo e 1,035 bilhão de pessoas viajando a turismo.

No Brasil segundo o Platum - Plano de Turismo Municipal (2010), o setor do turismo representa $7,1 \%$ do Produto Interno Bruto do país, são 5,5 milhões de pessoas exercendo funções relacionadas ao turismo. Além disto, a cidade de São Paulo recebeu 11,7 milhões de turistas, $42 \%$ a mais que em 2004 , esses turistas geraram uma receita de 9,6 bilhões de reias, 55\% a mais que em 2004 e tiveram a sua disposição aproximadamente 410 hotéis, o que representa também em números aproximados 42 mil quartos.

De acordo com Marino (2011), podem ser implantados 198 novos empreendimentos hoteleiros no país até o final de 2014, desses 76 estão previstos na região Sudeste, o que representa $38 \%$ do total dos projetos, 19 desses projetos estão previstos para o estado de São Paulo.

A implantação de novos empreendimentos hoteleiros pode demonstrar que os gestores acompanham os resultados do turismo na cidade de São Paulo e que o crescimento na demanda de viajantes abre espaço para um aumento na oferta de novos hotéis. Essa interação entre oferta e demanda é um dos exemplos existentes quando se observa os stakeholders de uma rede hoteleira.

Todos esses indicadores, mais a influência dos stakeholders, o acirramento da concorrência internacional no setor de viagens e hospedagem, a globalização da economia, o estabelecimento de padrões globais de qualidade, o potencial de negócio e expectativas de crescimento da demanda por hospedagem no Brasil, a disponibilidade financeira de parceiros e o investimento público em infra-estrutura colaboram para uma maior competição entre as redes hoteleiras (PROSÉRPIO, 2007).

Apesar desse aumento dos meios de hospedagem no Brasil, Aldrigui (2007), aponta que este crescimento vem esbarrando na qualidade na prestação de serviços e na resistência quanto ao uso de novas tecnologias, ainda que muito parecidos, os hotéis, deveriam buscar se diferenciar na forma com que prestam os serviços.

Por se tratar de uma prestação de serviços, os meios de hospedagem precisam assim como as outras empresas de serviço acompanhar tanto a qualidade tangível (estrutura) quanto a qualidade intangível (atendimento) do negócio (GUERRIER, 2000).

Segundo Petrocchi (2006), a qualidade do serviço hoteleiro está relacionada diretamente com "à competência, ao espírito de equipe e à hospitalidade dos funcionários" (PETROCCHI, 2006, p. 105).

Analisando então que uma das formas de estabelecer o valor de uma empresa é por intermédio da percepção dos clientes e que ela esta relacionada a performance pessoal do colaborador, já que tratamos de uma prestação de serviço, os meios de hospedagem precisam treinar as equipes para ser profissional, introduzido conceitos de qualidade e de hospitalidade, sem padronizar em excesso, perdendo assim a naturalidade do acolhimento (ALDRIGUI, 2007).

No setor hoteleiro, os gestores sabem que seus colaboradores são vistos como um dos pilares de uma organização. Segundo Friedman (2000, p. 75), “todas as organizações costumam dizer: as pessoas são nosso maior ativo, mas poucas delas, contudo, praticam o que pregam, quem dirá realmente acreditar nisso".

Medlik e Ingram (2002) enfatizam que um dos desafios do setor é a administração da força de trabalho e "com uma força de trabalho efetiva, os hotéis podem oferecer o nível requerido de qualidade de serviço e obter o nível requerido de lucro, mas o desafio é desenvolver e manter os funcionários" (MEDLIK; INGRAM, 2002, p.193). 

Múltiplos: Estanplaza, Travel Inn e Transamérica.

Antes de aprofundar as questões de gestão de pessoas no segmento hoteleiro há a necessidade de compreendermos as forma de administração hoteleira aplicadas no setor.

De acordo com Aldrigui (2007), a evolução desse segmento levou ao surgimento de diferentes formas de administração, de forma geral, um hotel pode ser independente ou pertencer a uma rede; as redes podem ser proprietárias dos hotéis, administrador hotéis ou franquear suas marcas a hotéis.

No caso específico desta pesquisa, os três objetos fazem parte de redes hoteleiras que segundo Aldrigui (2007), resultam da união de hotéis em torno de objetivos em comum, estar presentes em vários destinos, unir esforços em ações promocionais e conquista maior parcela de mercado. Além de redes hoteleiras as três empresas são companhias de administração hoteleira que operam ou administram propriedades pertencentes a outras empresas ou pessoas.

Do ponto de vista de prestação de serviços todas as formas de administração hoteleira apontadas pela autora, seguem a conceituação de serviços de Fitzsimmons, J.; Fitzsimmons M. (2005, p.30), que descrevem o serviço como uma experiência perecível, intangível, desenvolvida para um consumidor que desempenha o papel de co-produtor.

A qualidade do serviço prestado como já foi observada anteriormente esta sempre relacionada ao relacionamento entre receptor (hóspede) e o fornecedor (anfitrião), de acordo com Carlzon:

\begin{abstract}
Aos empregados da linha de frente, o líder deverá conferir a autoridade para atender às necessidades e problemas do cliente individual. (...) os empregados da linha de frente devem ser adequadamente treinados para que estejam habilitados a responder às necessidades especiais de cada cliente com rapidez e cortesia. Redistribuindo as responsabilidades desta maneira, as empresas poderão maximizar suas "horas da verdade". Os clientes felizes e satisfeitos se multiplicarão e, por conseguinte, uma importante vantagem competitiva estará assegurada. (CARLZON, p. 20, 2005)
\end{abstract}

A "hora da verdade", segundo Carlzon (2005), é o momento em que o receptor entra em contato com o fornecedor do atendimento, formando a imagem da empresa e gerando uma experiência que faz o receptor voltar ou não a utilizar os produtos e serviços da organização. Nesse sentido, Fitzsimmons, J.; Fitzsimmons M. (2005, p.146) apontam que a avaliação da qualidade surge ao longo do processo de prestação de serviço, o contato com o receptor é referido como um momento verdade, onde a oportunidade de satisfazer ou não a necessidade do receptor ocorre.
Observando a "hora da verdade" dentro da estrutura hoteleira, se faz necessário primeiramente compreender sua estrutura para depois compreender que áreas possuem este momento. A estrutura dos hotéis é dividida em departamentos, onde as funções essências da empresa e serviço são partilhadas entre eles. Não há um padrão, pois a estrutura pode se ajustar de acordo com o porte do hotel. Petrocchi (2007) discorre sobre as possibilidades de distribuições das funções pelos departamentos, agrupando pelo "volume de atividades, perfil das pessoas da organização, possibilidades de terceirização etc" (PETROCCHI, 2007, p. 30).

Segundo Aldrigui (2007), tradicionalmente, um hotel apresenta ao menos dois departamentos, o de hospedagem e o de alimentos e bebidas (também conhecido como AeB).

O departamento de hospedagem administra toda a experiência do hóspede, desde o momento em que solicita a reserva, passando por sua chegada e recepção, acomodação no quarto, utilização da estrutura do hotel e saída (fechamento de conta). O departamento de $\mathrm{AeB}$ administra todos os serviços ligados à produção de alimentos no hotel, atuando nas cozinhas, nos restaurantes, nas salas de eventos, nos bares e, também no serviço de quarto (room-service). (ALDRIGUI, 2007, P. 55)

Powers e Barrows (2004) estabelecem cinco bases para a departamentalização: função, produto ou serviço, território, clientes e processo. As bases função e produto, sãos utilizadas para a departamentalização no nível operacional, as bases território e cliente, são mais utilizadas nos níveis corporativos.

\section{TEORIA DOS STAKEHOLDERS}

O termo inglês stakeholders não possui tradução exata para o português, porém pode ser definido, segundo Freeman (1984, p. VI), como "diversos grupos ou indivíduos que influenciam ou podem ser influenciados por uma organização".

O termo stakeholder foi utilizado pela primeira vez em um memorando do Stanford Research Instittue (SRI) em 1963, segundo Freeman e Reed (1983), para generalizar a noção de stockholder como único grupo do qual a administração deveria ser responsável. O memorando destacou que estratégias de sucesso são aquelas que integram os interesses de todos os stakeholders, e não os interesses de apenas um grupo. A lista de stakeholders incluía originalmente os acionistas, empregados, fornecedores, clientes, financiadores e a sociedade.

Segundo Coradini, Sabino e Costa (2010), desde 1960 quando o termo stakeholder foi citado pela primeira vez, houve muitas outras publicações que 
abordaram o termo sobre diversos pontos de vista, estas diversas abordagens podem ser comprovadas pelos inúmeros trabalhos relacionados ao tema publicados nos últimos anos.

De acordo com Carroll e Buchholtz (2003) o conceito de stakeholder não pode ser compreendido sem que primeiro haja o entendimento do significado de stake - envolvimento de um indivíduo ou um grupo que participa de determinada decisão, seja ela por interesse, por direito ou por reivindicação, portanto, pode se verificar diferentes tipos de stakes.

Conforme Mitchell, Angle e Wood (1997), desde a publicação do primeiro livro de Freeman, a abordagem dos stakeholders tem sido essencial para a compreensão da empresa sobre seu papel e responsabilidade para com as partes interessadas ou envolvidas no negócio

A partir da abordagem sobre o problema conceitual de lidar com o ambiente externo da empresa Freeman (1984) propôs com objetivo de compreender as relações entre as partes interessadas e foi nesse contexto que surgiu o conceito de stakeholder. A nova ilustração denominada stakeholder view of firm, representa um exemplo de empresa e seus diversos stakeholders, neste caso os proprietários, clientes, ambientalistas, fornecedores, grupos de interesse especiais, funcionários, concorrência, mídia, governo e comunidade local. Para determinar estes stakeholders a empresas necessita de uma visão completo do negócio, do ambiente que se insere, do histórico da empresa, dentre outros.

Os stakeholders que influenciam ou são influenciados por uma empresa podem variar de companhia para companhia é possível explorar ainda que divisões cada grupo de stakeholder possuam, como por exemplo, o governo pode ser dividido em municipal, estadual e federal; os acionistas podem ser divididos em cidadãos, investidores e acionistas.

Outra forma de analisar a gestão dos stakeholders é separando eles em grupos de importância, segundo Freeman et al (2007) existem dois grupos, os stakeholders primários são os mais importantes para a empresa, sem eles as organizações não sobreviveriam; e os stakeholders secundários são aqueles que podem influenciar e afetar o desempenho das operações da empresa, mas não são vitais para sua existência.

A partir da análise dos stakeholders primários é interessante observar a equiparação entre acionistas e empregados, segundo Freeman et al (2007), estes personagens que fazem parte do contexto das redes hoteleiras pesquisadas, estão inseridos no mesmo grupo, porém enquanto os empregados possuem garantia por meio de contrato pré-definido sua participação no resultado da empresa, os acionistas podem ou não receber sua participação dependendo do resultado final. Os stakeholders primários são vitais para uma empresa, pois possuem interesses, objetivos, expectativas e responsabilidades diferenciadas em relação aos objetivos da empresa. Os administradores, segundo os autores, precisam compreender os valores e os objetivos deste primeiro grupo e priorizar o relacionamento para um melhor desempenho e alcance dos melhores resultados.

Por intermédio da análise dos stakeholders secundários, segundo Freeman et al (2007), é possível estabelecer como exemplo prático as ações governamentais que podem influenciar não somente a empresa, mas também os seus stakeholders primários, dentre eles os acionistas e os empregados.

A forma com que os stakeholders são classificados pode variar de acordo com os objetivos da empresa, segundo Wood (1990) apud Gonçalves et al. (2007), é importante classificar os stakeholders a partir do seu grau de importância para a organização, levando em consideração três fatores: (1) A identificação dos grupos e seus respectivos interesses; (2) A avaliação das relações entre esses grupos e a empresa, bem como entre eles próprios; (3) A incorporação dos tempos e processos em uma série de mapas que ilustrem as mudanças nas composições e forças que influenciam os grupos de stakeholders da organização.

Para Mitchell et al (1997), as organizações são capazes de estabelecer seus stakeholders a partir de três atributos: poder, legitimidade e urgência, cada qual pode ser obtido ou perdido conforme a sua relevância para a empresa.

Os argumentos de Mitchell et al (1997) são corroborados por Carrol e Buchholtz (2003) que estabelecem um paralelo entre os três atributos, enfatizando a conjunção em que os mesmos se encontram para estabelecer sua importância na gestão dos stakeholders. O poder é caracterizado pela possibilidade que um determinado ator tem para impor sua vontade; a legitimidade é a percepção generalizada ou pressuposta de que a ação de uma entidade é desejável, adequada ou apropriada, ela beneficia os grupos que estão mais próximos e exercem uma relação formal com a empresa; a urgência esta relacionado à rapidez com que se atendem as solicitações dos stakeholders, levando em consideração a atenção nos negócios ou a uma resposta. Tanto o poder quanto a legitimidade podem existir independente da existência de um ou de outro, mas também se sobrepõem garantindo sua relevância. Alguns grupos estabelecidos como legítimos, podem não exercer nenhuma influência quando analisados isoladamente, mas unidos podem gerar a autoridade e se fazer respeitar, conquistando assim privilégios pela intervenção da urgência.

Segundo Mitchell et al (1997) a intersecção destes três atributos, enfatiza a relevância para a empresa e a prioridade de atenção e cuidado com cada grupo, além de criar mais três grupos de stakeholders: os latentes - grupo que possui um dos três atributos, conforme quem os avalia, formado pelos tipos, 

Múltiplos: Estanplaza, Travel Inn e Transamérica.

adormecidos, discricionário ou reclamante. O grupo formado pela interseção de dois grupos de interesse: dominante, perigoso e dependente, tendo dois dos três atributos possíveis, e os definitivos, que é formado pelos grupos que possuem os três atributos.

A partir dos diferentes pontos de vista de cada autor sobre os stakeholders cabe as empresas estabelecerem quem são eles e qual o nível de influência entre as partes, segundo Freeman et al (2007), existem várias formas de definir e descrever as partes interessadas de uma empresa, cabe a ela estabelecer seu mapa, considerando o nível de relacionamento entre os grupos e indivíduos.

Segundo Junqueira e Wada (2011):

O envolvimento das organizações com seus grupos de interesses requer conhecimento para que se tenha uma relação que seja construtiva e produtiva para os envolvidos no negócio. Compreender as expectativas da sociedade em relação à conduta social e ética das organizações se tornou essencial, a pressão exercida por grupos que podem estar ligados, direta ou indiretamente, ao negócio já é uma realidade. (Junqueira; Wada, 2011, p. 104).

Para poder correlacionar a teoria e gestão dos stakeholders aplicada a área de recursos humanos das três redes hoteleiras, faz-se necessário um estudo aprofundado acerca de seus aspectos principais, stakeholders relevantes e formas de gestão.

\section{RECRUTAMENTO E SELEÇÃO}

Antes de conceituar a área recrutamento e seleção e correlacioná-la com o tema da pesquisa é necessário estabelecer o que é a Administração de Recursos Humanos (ARH), também conhecida como Gestão de Recursos Humanos (GRH).

De acordo com Albuquerque (1992):

A gestão de Recursos Humanos da empresa competitiva, na nova concepção, deverá ter como características principais: função de recursos humanos na cúpula das organizações; gestão planejada e proativa; descentralizada e compartilhada (cada gerente deve gerir sua equipe); transparente; flexível; adulta (sem paternalismos); orientada para resultados; estimuladora da inovação e da criatividade. (Albuquerque, 1992, p. 28)

Segundo Lashley e Morrison (2004), a Gestão de Recursos Humanos nas empresas de serviços tende a ser influenciada pelo tipo de serviço prestado, por intermédio deste ponto vista Tanke (2004), aponta que todos os gerentes dentro das estruturas dos meios de hospedagem são gerentes de recursos humanos, já que possuem responsabilidades que incluem o relacionamento com pessoas e que representam a imagem do produto vendido aos hóspedes.

Este perfil de gerente que tem foco na administração de recursos humanos desenvolve seu trabalho segundo Tanke (2004), implantado estratégias, planos e programas para atrair, motivar, desenvolver, remunerar e reter as melhores pessoas para a empresa, a fim de cumprir as metas organizacionais e os objetivos operacionais.

Para obter resultados na relação entre colaboradores e os serviços faz-se necessário realizar contratações efetivas. Tendo "o contato do funcionário com o hóspede exige a contratação de pessoas que tenham o perfil adequado para lidar com o público. Assim, começa no processo de recrutamento e seleção o caminho do sucesso do hotel." (Petrocchi, 2006, p. 106).

De acordo com Mullins (2001), no setor hoteleiro as pessoas fazem parte de um dos principais pontos de sustentação das vantagens competitivas e para garantir que os hotéis atraiam os melhores profissionais do mercado, as estratégias de recrutamento precisam ser revisadas e atualizadas regularmente (Mullins, 2001).

Segundo Tanke (2004), o recrutamento pode ser definido como processo pelo qual a empresa seleciona o candidato melhor qualificado para um cargo vago. Além disto, se a empresa busca atrair pessoas com características específicas (formação educacional, aptidões e experiência para desempenhar as tarefas) é necessário valer de descrições de cargos e especificações de funções.

A comunicação de existência das vagas pode ser feita de duas formas segundo Ribeiro (2006), internamente ou externamente, sempre visando atrair candidatos potencialmente qualificados. De acordo com Tanke (2004) as fontes internas incluem aquelas existentes no âmbito de sua própria organização de hospitalidade, são as promoções e transferências; as fontes externas são aquelas que não fazem parte de sua organização.

Para Gil (2007), há nove formas de se realizar o recrutamento, sendo que a própria nomenclatura já explica o processo. Sendo elas: recrutamento dentro da empresa, cartazes, recomendações, pessoal dispensado, agências, associados profissionais, anúncios, headhunter ${ }^{6}$, internet.

$\mathrm{O}$ destaque para o recrutamento dentro das atividades da administração de recursos humanos se faz necessário segundo Carvalho e Nascimento (1997), pois a sua execução incorreta pode provocar prejuízos dentro da empresa, com destaque para:

\footnotetext{
${ }^{6}$ Headhunters - caçadores de talentos, que atuam somente na busca de profissionais extremamente qualificados ou difíceis de serem localizados pela sua área de atuação (MARRAS, 2000).
} 
a) (...) a) alto índice de giro de pessoal ("turn over"); b) aumento substancial dos custos de recrutamento; c) ambiente de trabalho comprometido com funcionários pouco qualificados para o pleno exercício de suas funções (CARVALHO; NASCIMENTO, 1997, p. 78).

Segundo Tanke (2004), uma das maneiras que podem evitar a execução incorreta do recrutamento e consequentemente possibilitarem maior respaldo para o processo é a utilização das opções de recrutamento online. Esta modalidade permite obter um maior número de currículos e viabiliza mais candidatos para serem entrevistas, além de obter currículos de pessoas de fato interessadas e qualificadas, às vezes, para as vagas (Tanke, 2004).

De acordo com Costa (2002), o uso de sistemas online, mídia eletrônica e redes de telecomunicação podem ser denominadas como $e-R H$ ou $\mathrm{Rh}$ virtual, nomenclatura segundo Jones (1998) que estabelece o RH como modelo de gestão de Recursos Humanos baseado em tecnologia de informação altamente avançada. Além disso, as organizações com site próprio adotaram o "Trabalhe Conosco" possibilitando que os interessados as vagas na empresa preencham um currículo online.

O recrutamento está diretamente ligado com a seleção dos colaboradores, que é a continuidade do processo para se contratar um indivíduo. A seleção de novos colaborados tem a finalidade central de "escolha da pessoa certa para o cargo certo, ou seja, escolha, entre os candidatos recrutados" (Ribeiro, 2006, p. 52). Neste momento há diversas técnicas adotadas pelas empresas a fim de verificar se o candidato tem o perfil da empresa e da vaga em si. Os métodos mais comuns são: análise de currículo, entrevistas, dinâmicas em grupos e testes psicotécnicos.

Segundo Tanke (2004), a etapa da entrevista do processo de seleção pode ser definida como uma forma de comunicação de duas mãos que tem como objetivo final reconhecer tanto as habilidades do candidato para realizar as tarefas exigidas da função quanto à capacidade para adaptar-se ao ambiente da empresa.

De acordo com Mullins (2004), a entrevista de seleção é na maioria das vezes o elemento central para o processo de seleção já que implica em uma interação de personalidades que tem como objetivo "explorar" o candidato por intermédio de perguntas significativas, objetivas e práticas.

As entrevistas podem divididas em três grupos, segundo Tanke (2004), a entrevista estruturada, onde é estabelecida uma série de questões elaboradas com base nos pré-requisitos da vaga; a entrevista não estruturada, onde o entrevistador estabelece questões gerais para os candidatos, mas seus principais questionamentos são formulados a partir das respostas do candidato; e a entrevista semiestruturada, onde uma quantidade mínima de questões para todos os candidatos é formulada e a partir delas o entrevistador estabelece perguntas adicionais.

Além dessas divisões de modelos de entrevistas, Mullins (2004) considera também as entrevistas em movimento como possibilidade para a seleção de novos colaboradores, nela o entrevistador convida o candidato a conhecer a empresa durante o tour faz as perguntas pertinentes a função pretendida. Essa modalidade permite que o candidato conheça melhor o ambiente de trabalho da empresa e possibilita ao entrevistador captar repostas mais naturais.

O processo de seleção não é composto apenas pela entrevista, de acordo com Tachizawa (2001), as técnicas de seleção podem ser divididas em: entrevista, provas de conhecimento e capacidade, testes psicométricos, testes de personalidade e técnicas de simulação.

Tanke (2004) também considera outras etapas além da entrevista com o candidato, dentre estas etapas estão entrevista de aptidão, testes de inteligência, testes de personalidade e testes de integridade.

Por intermédio da análise dos testes assinalados por Tanke (2004) e das características dos domínios da hospitalidade apontados por Lashley (2004), é possível estabelecer que a união entre estes dois pontos poderia contribuir de alguma forma na seleção de colaboradores para os meios de hospedagem.

\section{APRESENTAÇÃO E ANÁLISE DE DADOS}

$\mathrm{Na}$ análise comparativa, foram utilizadas todas as fontes de evidências, pesquisa bibliográfica sobre os temas domínios da hospitalidade, segmento hoteleiro, stakeholders e recrutamento e seleção; seguido da aplicação da pesquisa de acordo com o protocolo de estudo de casos múltiplos, com objetivo de demonstrar as semelhanças e diferenças entre as três redes hoteleiras pesquisadas, por intermédio do cruzamento das informações coletadas, conforme sugere Yin (2010, p. 144), "com a triangulação dos dados, os problemas potencias de validade do construto também podem ser abordados, porque as múltiplas fontes de evidência proporcionam, essencialmente, várias avaliações do mesmo fenômeno".

Para construção da análise comparativa, os dados e informações foram selecionados e analisados em profundidade para depois serem organizados de forma a identificar os fatores determinantes que possibilitaram a comparação dos fatos. Para isso, as informações foram organizadas abaixo em tabelas, de maneira a identificar fatores que possibilitem a comparação dos registros de cada rede estudada. 
Os Domínios da Hospitalidade e a Gestão de Stakeholders em Recrutamento e Seleção Estudo de Casos Múltiplos: Estanplaza, Travel Inn e Transamérica.

\section{Stakeholders}

Com objetivo de identificar os principais stakeholders das três redes hoteleiras estudadas, as informações coletadas nas entrevistas e classificadas com alta e média influência foram agrupadas para comparação dos estudos de caso.

\begin{tabular}{|l|c|c|c|}
\hline \multicolumn{1}{|c|}{ Grupos } & $\begin{array}{c}\text { Estanplaza } \\
\text { Hotels }\end{array}$ & $\begin{array}{c}\text { Hotéis } \\
\text { Transamérica }\end{array}$ & $\begin{array}{c}\text { Travel Inn } \\
\text { Hotéis }\end{array}$ \\
\hline Governos & $\mathrm{X}$ & $\mathrm{X}$ & $\mathrm{X}$ \\
\hline Comunidade Local & $\mathrm{X}$ & & $\mathrm{X}$ \\
\hline Grupos de defesa do consumidor & & $\mathrm{X}$ & $\mathrm{X}$ \\
\hline Proprietários & & $\mathrm{X}$ & $\mathrm{X}$ \\
\hline Clientes & $\mathrm{X}$ & & $\mathrm{X}$ \\
\hline Ambientalistas & & & $\mathrm{X}$ \\
\hline Fornecedores & & $\mathrm{X}$ & $\mathrm{X}$ \\
\hline Grupos de interesses especiais & & $\mathrm{X}$ & $\mathrm{X}$ \\
\hline Funcionários & $\mathrm{X}$ & $\mathrm{X}$ & \\
\hline Concorrência & $\mathrm{X}$ & $\mathrm{X}$ & \\
\hline Midia & $\mathrm{X}$ & $\mathrm{X}$ & $\mathrm{X}$ \\
\hline Centros de Ensino & $\mathrm{X}$ & & \\
\hline Sindicatos & & & \\
\hline
\end{tabular}

Quadro 1 - Stakeholders classificados com Alta e Média influência pelas redes hoteleiras Fonte: Quadro elaborado pelo autor com base nas entrevistas

A partir da análise Quadro 1, foi possível notar que dos onze grupos apresentados, nove foram citados pelas redes hoteleiras, dois foram acrescentados, Centros de Ensino e Sindicatos, e mesmo com estruturas de recrutamento e seleção diferentes as três redes hoteleiras citaram quatro grupos iguais, Governos, Clientes, Funcionários e Concorrência.

Quando os principais líderes de Recrutamento e Seleção de cada rede foram questionados sobre a identificação espontânea dos grupos de stakeholders eles citaram, Sr. Fabiano Orso: Concorrência - direta e indireta, Centros de Ensino e Funcionários; Sra. Flávia Silva: Concorrência, Centros de Ensino, Funcionários; e Sra. Rianne Vasconcellos: Funcionários.

A partir desse resultado, o pressuposto: " $A$ área de recrutamento e seleção não considera que existam impactos das contratações nos stakeholders das redes hoteleiras", foi refutado. No decorrer das entrevistas foi possivel observar que os gestores das redes hoteleiras selecionaram nove dos onze grupos como "alta" ou "média" influência, além disto, foram acrescentados outros dois grupos, Centros de Ensino e Sindicatos, dessa forma não há como não afirmar que existem impactos das contratações nos stakeholders das redes hoteleiras.

\section{Gestão de Recrutamento e Seleção}

Com base nas repostas dadas pelos gestores das três redes hoteleiras, foi possível estabelecer o Quadro 2, como comparativo de modelo de gestão.

\begin{tabular}{|l|c|c|c|}
\hline $\begin{array}{c}\text { Gestão de Recrutamento e } \\
\text { Seleção }\end{array}$ & $\begin{array}{c}\text { Estanplaza } \\
\text { Hotels }\end{array}$ & $\begin{array}{c}\text { Hotéis } \\
\text { Transamérica }\end{array}$ & $\begin{array}{c}\text { Travel Inn } \\
\text { Hotéis }\end{array}$ \\
\hline Centralizado & $\mathrm{X}$ & $\mathrm{X}$ & \\
\hline Descentralizado & & & $\mathrm{X}$ \\
\hline
\end{tabular}

Quadro 2 - Modelo de gestão de Recrutamento e Seleção nas redes hoteleiras

Fonte: Quadro elaborada pelo autor com base nas entrevistas

Segundo a entrevistada Sra. Rianne Vasconcellos, a Travel Inn não possui um R\&S Corporativo, “(...) cada unidade a Travel Inn tem a sua pessoa específica que cuida de recursos humanos, mas ela é orientada por esta empresa especializada que nós temos (...) Persona Recursos Humanos."

Mesmo com essa diferença de modelo de gestão de Recrutamento e Seleção, as três redes possuem etapas de seleção semelhantes conforme apresentado na Figura 2. 
Os Domínios da Hospitalidade e a Gestão de Stakeholders em Recrutamento e Seleção Estudo de Casos Múltiplos: Estanplaza, Travel Inn e Transamérica.

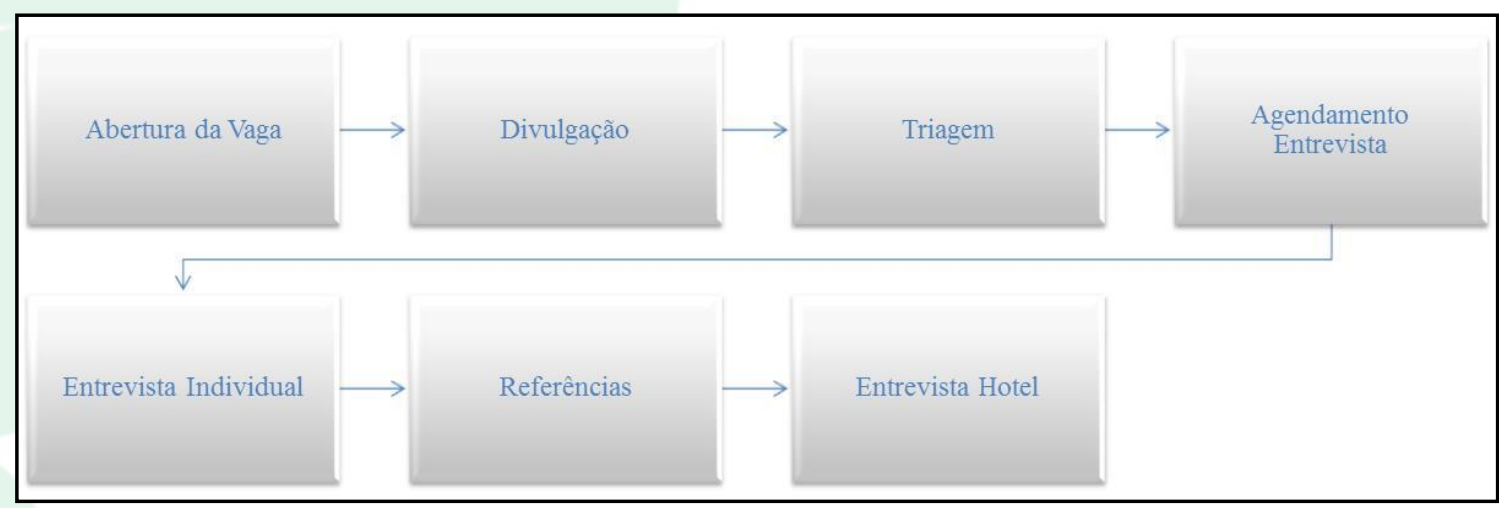

Figura 2 - Fluxo de recrutamento padrão entre as redes hoteleiras Fonte: Figura elaborada pelo autor com base na entrevista

Houve dois pontos divergentes entre as redes, o primeiro na Transamérica, a Sra. Flávia Silva aponta que "(...) a partir do momento em que a gente recebe uma abertura de vaga, a gente vai verificar o que nós temos no nosso banco (...)", e o segundo ponto na Estanplaza, o Sr. Fabiano Orso citou que “(...) a gente traz esses comentários para uma dinâmica, apresenta isso aos candidatos e o trabalho deles é descobrir o que foi feito para (...) que o cliente sentiu para escrever aquele comentário".

As três redes selecionadas para o estudo de casos múltiplos utilizam de meios de seleção internos e externos, dentre os externos estão os apresentados no Quadro 3.

\begin{tabular}{|l|c|c|c|}
\hline Meios de Divulgação & Estanplaza Hotels & $\begin{array}{c}\text { Hotéis } \\
\text { Transamérica }\end{array}$ & $\begin{array}{c}\text { Travel Inn } \\
\text { Hotéis }\end{array}$ \\
\hline Sites de emprego & $\mathrm{X}$ & $\mathrm{X}$ & $\mathrm{X}$ \\
\hline Anúncios em Jornais & $\mathrm{X}$ & $\mathrm{X}$ & $\mathrm{X}$ \\
\hline Centros de Ensino & $\mathrm{X}$ & & \\
\hline Naia & $\mathrm{X}$ & & \\
\hline Nube & $\mathrm{X}$ & $\mathrm{X}$ & \\
\hline CIEE & $\mathrm{X}$ & $\mathrm{X}$ & $\mathrm{X}$ \\
\hline Redes Sociais & $\mathrm{X}$ & & $\mathrm{X}$ \\
\hline Site da rede & & & \\
\hline Sindicato & & & \\
\hline
\end{tabular}

Quadro 3 - Meios de divulgação das redes hoteleiras

Fonte: Quadro elaborado pelo autor com base na entrevista

Mesmo com o trabalho de divulgação de vagas por meios externos, as três redes também fazem uso de recrutamento interno.

Os modelos de seleção utilizados pelas três redes hoteleiras são validados por Lashley (2011), que afirma que a forma como um meio de hospedagem atrai seus candidatos é fundamental para o sucesso do recrutamento, por esta razão ele define duas fontes de candidatos, a primeira interna e a segunda externa.

\section{Domínios da Hospitalidade}

A partir das repostas dadas pelos gestores das três redes hoteleiras no bloco, foi possível definir que existem relações entre os domínios da hospitalidade e as áreas dos hotéis e essas relações estão relacionadas ao tipo de serviço executado pelos colaboradores, independente do nível em que elas ocorram.

Em todas as entrevistas os gestores citaram comportamentos e características similares às apresentadas por Lashley e Morrison (2004), conforme Figura 3. 
Estanplaza Hotels

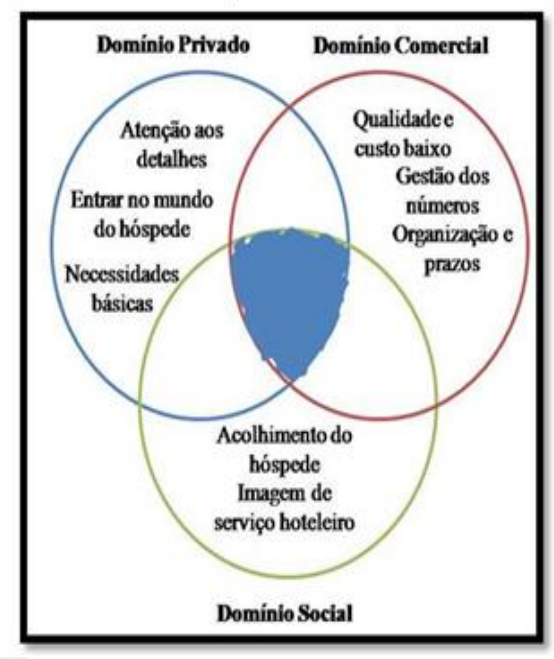

Hotéis Transamérica

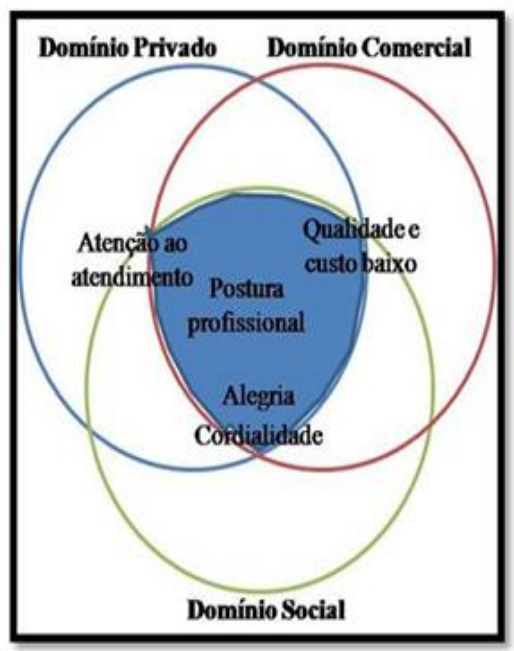

Travel Inn Hotéis

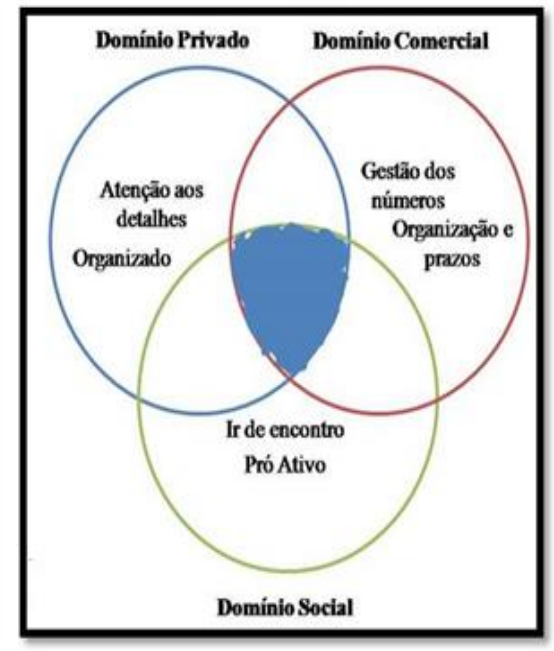

Figura 3 - Domínios da Hospitalidade nas redes hoteleiras Fonte: Figura elaborada pelo autor com base na entrevista

Para estabelecer o tamanho da área de intersecção entre os domínios não foi aplicado nenhum tipo de cálculo de volume, o tamanho e proximidade entre as características e o espaço de intersecção foi estabelecido para que houvesse a possibilidade de uma análise visual das repostas dos entrevistados e a compreensão de quanto à rede hoteleira considera importante a presença dessas características em seus colaboradores.

A variação entre o tamanho das intersecções entre os domínios, Transamérica é maior que Estanplaza e Travel Inn, é referente ao ponto de vista dos gestores da Transamérica, que consideram que uma maior parte das características são essências para os colaboradores.

Contudo, quanto maior a sobreposição dos domínios da hospitalidade, maior é importância para rede hoteleira em selecionar pessoas que tenham características que unem os domínios privado, social e comercial.

Quando questionados se as ferramentas utilizadas por Recrutamento e Seleção consideravam as características e comportamentos dos candidatos, os gestores afirmaram que parte delas é contemplada nas dinâmicas, entrevistas ou testes, segundo Sr. Fabiano Orso, os testes “(...) nos ajudam a qualificar isso, a localizar isso nas pessoas". Para Sra. Rianne Vasconcellos:

“(...) a gente busca nesta avaliação, a gente procura chegar o mais próximo possível numa avaliação, numa entrevista ou na análise do que a pessoa escreveu, o perfil psicológico, psicotécnico que ela fez, são ferramentas que você usa para chegar o mais próximo possivel daquele perfil ideal pra aquele cargo (...)" (Rianne Vaconcellos, Gerente Geral na Travel Inn Hotéis 2013).

De acordo com a Sra. Flávia Silva, “(...) a gente consegue identificar através da resposta que ele dá, através dos testes que nós aplicamos fechar um laudo, uma conclusão daquele candidato".

Contudo, o pressuposto: "As etapas de seleção consideram as características dos domínios da hospitalidade no momento da avaliação dos candidatos", foi confirmado, durante as entrevistas foi possível comprovar que as ferramentas de seleção utilizadas pelas três redes hoteleiras, sejam os testes, dinâmicas, provas ou entrevistas, levam em consideração as características dos domínios da hospitalidade, fora outras características específicas das funções ou da rede. Assim como o pressuposto: "Os processos de recrutamento consideram as características dos domínios da hospitalidade", também foi confirmado, observou-se que durante os processo de recrutamento, nas três redes hoteleiras, as características dos domínios da hospitalidade são consideradas, fora outras características específicas das funções ou da rede.

\section{CONCLUSÕES}

Para responder a questão da pesquisa, "Quais são as características dos domínios da hospitalidade consideradas no processo de recrutamento e seleção?", foi necessário reunir ações e comportamentos que os gestores citaram como parte integrante de cada 
domínio e traduzi-los em características, conforme apresentado na Figura 2.

Após a problemática, foi estabelecido o objetivo principal da pesquisa, "Os processos utilizados em recrutamento e seleção estabelecem características dos domínios da hospitalidade", foi alcançado por intermédio da união de dois pontos apresentados durante as entrevistas com os gestores, o primeiro esta relacionado ao modelo padrão de fases para recrutar e selecionar pessoas conforme e Figura 2, similar ao que também foi apresentado por Tanke (2004), Mullins (2004) e Tachizawa (2001); e o segundo ponto é a confirmação que para diferentes áreas são consideradas diferentes comportamentos e esses comportamentos podem ser relacionados aos domínios da hospitalidade, conforme apresentado na Figura 3.

Além do objetivo geral estabelecido e alcançado, objetivos específicos também fazem parte da estrutura da pesquisa, o primeiro objetivo específico "Observar a dinâmica do processo de recrutamento e seleção das redes hoteleiras"; foi alcançado por intermédio de duas vias, a primeira, a partir da observação direta da rotina de recrutamento e seleção feita na Estanplaza e a segunda por meio das entrevistas com os gestores da Estanplaza, Transamérica e Travel Inn, que descreveram todas as etapas tanto de recrutamento quanto de seleção dos candidatos, por se tratarem de etapas similares foi possível estabelecer um padrão conforme apresentado na Figura 2.

O segundo objetivo específico estabelecido e alcançado foi "Analisar o conteúdo relacionado aos domínios da hospitalidade nas ferramentas utilizadas no processo de recrutamento e seleção", as mesmas que já foram identificadas no objetivo geral. De acordo com Sr. Fabiano Orso, Gerente de Recrutamento e Seleção, as ferramentas utilizadas pela Estanplaza são "redação, (...), o Palográfico, o Teste de Atenção Concentrada e o Disc". Ainda segundo Sr. Orso, cada um desses testes tem como objetivo identificar características essências para o sucesso do colaborador na função e "nos ajudam a qualificar isso, a localizar isso nas pessoas".

$\mathrm{Na}$ rede Hotéis Transamérica, a Sra. Vera Lúcia Castro, aponta que após a abertura da vaga, o candidato passa por "entrevistas, tem testes psicológicos, tem teste de avaliação grafológica, tem a parte técnica, tem o inglês falado, escrito, (...) e tudo isso é desenvolvido internamente na equipe de recrutamento e seleção, mas passam sim por vários testes", a partir da análise desses testes os analistas de recrutamento e seleção conseguem estabelecer um laudo com aprovando ou não o candidato.

Segundo a Sra. Rianne Vasconcellos, gestora da Travel Inn, a rede utiliza "testes psicológicos que vai depender também do nível do pessoal", outro entrevistado também citou "as fichas cadastrais, a redação, a avaliação da chefia direta, a avaliação da gerência geral", como ferramentas para análise do perfil comportamental dos candidatos.

Com base nos apontamentos da entrevistada Sra. Nathia Andrade, as empresas que prestam o serviço de recrutamento e seleção para redes hoteleiras também utilizam "teste comportamental de liderança baseado em comportamentos, (...) a ferramenta do Quantum, ou com o próprio Disc”, para determinar a continuidade dos candidatos nos processo.

O terceiro objetivo específico estabelecido e alcançado foi "Conhecer os stakeholders dessa área" (Recrutamento e Seleção), conforme já apresentado anteriormente no Quadro 3, Freeman (1984, p. VI) aponta que stakeholders são "diversos grupos ou indivíduos que influenciam ou podem ser influenciados por uma organização", por intermédio da entrevista com os gestores das redes hoteleiras foi possível conhecer esses stakeholders e também dividi-los em grupos de maior ou menor influência, assim como Freeman et al (2007), também dividiu, os stakeholders em primários, os considerados mais importantes para a empresa, sem eles as organizações não sobreviveriam; e os considerados stakeholders secundários, aqueles que podem influenciar e afetar o desempenho das operações da empresa, mas não são vitais para sua existência.

A partir da união dos dados coletados nas três redes hoteleiras com a vivência prática da área de $R \& S$ do pesquisador, foi possível notar que tanto a Estanplaza quanto a Transamérica possuem um cuidado maior no recrutamento e seleção dos candidatos, isso porque as políticas e processos estão centralizados em uma área que trabalha sob a luz da visão e missão das empresas, já no caso da Travel Inn, por não ter uma área de recrutamento e seleção centralizada, demonstrou indícios de ter esse processo mais solto, o que pode diminuir o número de acertos nas contratações.

Portanto a partir dos dados levantados, algumas das contribuições práticas possíveis das constatações dessa pesquisa é a inclusão de comportamentos e características área nas descrições de cargos, a utilização de testes com fundamentos na psicologia no maior número de funções possíveis e a implantação de laudos comportamentais para os candidatos aprovados para acompanhamento durante o período deles na empresa.

\section{CONSIDERAÇÕES FINAIS}

Os serviços hoteleiros na cidade de São Paulo obtiveram nos últimos anos resultados positivos quanto a sua receita e demanda de turistas, esses resultados levam os hotéis a competirem não apenas pelos melhores clientes, mas também pelos melhores colaboradores. 

Múltiplos: Estanplaza, Travel Inn e Transamérica.

Com base nessa busca pelos melhores colaboradores, analisar os modelos de gestão da área de recrutamento e seleção, desde as etapas do processo de seleção até as partes que influenciam este processo pode ser uma forma de aperfeiçoar o modelo atual de recrutamento e seleção de colaboradores para os serviços hoteleiros.

A compreensão das influências das partes interessadas nos processos de recrutamento e seleção apenas será possível se considerada a teoria dos stakeholders, que está cada vez mais sendo utilizadas por gestores e por pesquisadores, por considerar todas as partes que influenciam ou podem ser influenciadas nos processos. De acordo com Freeman (1984), para entender a influência que os diversos grupos de interesse exercem sobre as estratégias organizacionais, é importante que os gestores identifiquem quem são esses grupos e de que forma os objetivos da empresa influenciam e são influenciados por eles, entendendo as suas expectativas e como estas expectativas podem ser atendidas.

A análise comparativa se iniciou com a identificação dos stakeholders da área de recrutamento e seleção, feita por intermédio de um mapa conceitual, pré-estabelecido com onze grupos de stakeholders, durante essa etapa verificou-se a existência de quatro grupos selecionados pelos gestores das redes hoteleiras como "alta" ou "média" influência, Governo, Clientes, Funcionários e Concorrência; exceto pelo Governo, todos os outros fazem parte do que Freeman et al (2007) aponta como stakeholder primário - os mais importantes para a empresa, sem eles as organizações não sobreviveriam. Além disso, dos onze grupos apresentados, nove foram citados por pelo menos uma rede hoteleira e mais dois grupos foram acrescentados, Centros de Ensino e Sindicatos.

Como os serviços hoteleiros têm em sua essência a prática da hospitalidade, a forma que essa pesquisa estabeleceu para tentar contribuir nos processos de recrutamento e seleção, foi por intermédio da caracterização das atividades dos domínios da hospitalidade, ou seja, a partir de cada domínio da hospitalidade, buscou-se compreender se características individuais podem estar por trás delas e a partir daí encaixá-las dentro dos departamentos de um hotel e dentro das atribuições das funções desses departamentos.

Buscou-se apresentar nesse trabalho, por meio da revisão bibliográfica e da investigação empírica, implicações que envolvessem maior conhecimento sobre o tema abordado. No entanto, durante o processo de construção da pesquisa, foi possível notar que novos caminhos poderiam ter sido traçados, a partir dos novos questionamentos que foram surgindo, dentre eles: a diferença entre as descrições de cargos para as mesmas funções entre as redes hoteleiras, a utilização dos questionários respondidos pelos hóspedes como ferramenta de avaliação dos colaboradores e o desenvolvimento das características dos domínios da hospitalidade após a contratação dos colaboradores. Nesse estudo foram entrevistados os principais gestores que estão ligados a área de recrutamento e seleção, para aprimoramento e plenitude desse estudo seria prudente a investigação com um número maior de entrevistados do mesmo grupo e ampliação dos grupos pesquisados, tais como os colaboradores, comunidade local e centros de ensino.

\section{REFERÊNCIAS}

Albuquerque, L. G. Competitividade e recursos humanos. Revista de Administração. São Paulo v. 27, n. 4, out-dez 1992, p. 16-29.

Aldrigui, M. Meios de Hospedagem. São Paulo: Aleph, 2007.

BNDES. Qualidade na hotelaria: o papel de recursos humanos. Disponível em <http://www.bndes.gov.br/SiteBNDES/export/sites/ default/bndes_pt/Galerias/Arquivos/conhecimento/s etorial/get4is23.pdf.> Acesso em: 15 de jul. de 2012.

Beni, M. Análise estrutural do turismo. São Paulo: Senac, 2001.

Carlzon, J.. A Hora da Verdade. Rio de Janeiro: Sextante, 2005.

Carroll, A. B.; Buchholtz, A. K.. Business and Society: Ehics and Stakeholder Management. Austrália: Thomson South Western, 2003.

Carvalho, A.; Nascimento, L. P.. Administração de Recursos Humanos. São Paulo: Pioneira, 1997.

Coradini, C., Sabino, M. d. S.; Costa, B. K.. Teoria dos Stakeholders: Estudo da Arte Produzido no Brasil. In: XIII SEMEAD - Seminários em Administração FEA/USP. São Paulo: SEMEAD, 2010.

Costa, T. R.; Fischer, A. L. e-RH: o impacto da tecnologia para gestão competitiva de recursos humanos. TCC de administração da Universidade de São Paulo, 2002.

Dencker, A.; Da Via, $\quad$ S.. Pesquisa empírica em ciências humanas. São Paulo: Futura, 2001

Estanplaza, H.. Estanplaza Hotels - Grupo Estanplaza. Disponível em: <http://www.estanplaza.com.br/grupo-estanplaza/>. Acesso em: 04 ago. 2012. 
Os Domínios da Hospitalidade e a Gestão de Stakeholders em Recrutamento e Seleção Estudo de Casos Múltiplos: Estanplaza, Travel Inn e Transamérica.

Fitzsimmons, J.; Fitzsimmons, M.. Administração de serviços: operações estratégia e tecnologia da informação. Porto Alegre: Bookman, 2005.

Freeman, R.. Strategic Management: a stakeholder approach. Minnesota: Pitman, 1984.

Freeman, R.; Reed, D. L.. Stockholders and Stakeholdres: A New Perspective on Corporate Governance. California Management Review, 1983, p.93-94.

Freeman, R.; Harisson, J.; Wicks, A.. Managing for stakeholders: survival reputation. New Haven and London: Yale University Press, 2007.

Friedman, B.; Hatch, J.; Walker, D. M. Como atrair, gerenciar e reter capital humano: da promessa à realidade. São Paulo: Futura, 2000.

Gil, A. C.. Gestão de Pessoas: enfoque nos papéis profissionais. São Paulo: Atlas, 2007.

Guerrier, Y.. Comportamento organizacional em hotéis e restaurantes. São Paulo: Futura, 2000.

Jones, J. W.. Virtual HR. Crisp Publications. California, 1998.

Junqueira, R.R., Wada, E.K. (set./dez. 2011) Stakeholders: estratégia organizacional e relacionamento. Estudo de casos múltiplos do setor hoteleiro. Revista Ibero-Americana de Estratégia RIAE. 10(3), 94-125.

Lashley, C; Morrison, A.. Em busca da Hospitalidade Perspectivas para um mundo globalizado. Barueri: Manole, 2004.

Lashley, C. . Adminsitração de pequenos negócios de hospitalidade. Rio de Janeiro: Elsevier, 2011.

Marino, J. E.. Investimentos no Brasil: Hotéis e Resorts. São Paulo: BSH Travel Research, 2011.

Marras, J. P.. Administração de recursos humanos: do operacional ao estratégico. São Paulo: Futura, 2000.

Medlik, S.; Ingram, H.. Introdução à hotelaria: gerenciamento e serviços. Rio de Janeiro: Elsevier, 2002.

Mitchell, R.; Agle, D. J.; Wood, B. R.. Toward a Theory of Stakeholder Identification and Salience: Defining the Principle of Who and What Really Counts. Academy of Management Review, jun, 1997, p. 853-886.
Mullins, L. J.. Gestão da hospitalidade e comportamento organizacional. Porto Alegre: Bookman, 2004.

Oliveira, P. F., Wada, E.K. (mai./ago. 2012) Stakeholders e Apart-Hotéis: Estudo de casos múltiplos. Revista Ibero-Americana de Estratégia RIAE. 11(2), 145-169.

OMT, O. M. International Tourism To Continue Robust Growth IN 2013. DISPONÍVEL EM OMT: <HTTP://MEDIA.UNWTO.ORG/EN/PRESSRELEASE/2013-01-28/INTERNATIONALTOURISM-CONTINUE-ROBUST-GROWTH2013>. ACESSADO EM 07 DE ABR. DE 2013.

Petrocchi, M.. Hotelaria: Planejamento e Gestão. São Paulo: Pearson Prentice Hall, 2007.

Platum. Platum 2011-2014. Plano de Turismo Municipal. São Paulo: São Paulo Turismo, 2010.

Powers, T.; Barrows, C. W.. Administração no setor de hospitalidade: turismo, hotelaria, restaurante. São Paulo: Atlas, 2004.

Proserpio, R. O avanço das redes hoteleiras internacionais no Brasil. São Paulo: Aleph, 2007.

Quadros, A. H.. A hospitalidade e o diferencial competitivo das empresas prestadoras de serviço. Revista Hospitalidade. São Paulo, v. VIII, n.1, janjun 2011, p. 43-57.

Ribeiro, A. L.. Gestão de Pessoas. São Paulo: Saraiva, 2006.

Silveira, E. S.. Hospitalidade: notas conceituais, antropológicas e históricas. In: R. Dias; M. A. Pimenta. Gestão de hotelaria e turismo. São Paulo: Pearson Prentice Hall, 2005, p. 127-148.

Tachizawa, T.; Ferreira, V. C.; Fortuna, A. A.. Gestão com pessoas. Uma abordagem aplicada às estratégias de negócios. Rio de Janeiro: FGV, 2001.

Tanke, M. L.. Administração de recursos humanos em hospitalidade. São Paulo: Pioneira Thomson Learning, 2004.

Telfer, E.. Food for Thought: Philosophy and Food. London: Routledge, 1996.

Transamérica, H.. Hotéis Transamérica. Disponível em: < http://www.travelinn.com.br/2009/redehoteis.asp> Acesso em: 25 de jan. de 2013. 
Os Domínios da Hospitalidade e a Gestão de Stakeholders em Recrutamento e Seleção Estudo de Casos Múltiplos: Estanplaza, Travel Inn e Transamérica.

Travel Inn, H.. Travel Inn Hotéis. Disponível em: < http://www.transamericagroup.com.br/br/empresa_t hg.aspx > Acesso em: 25 de janeiro de 2013.

Wada, E. K.. Domínios de hospitalidade de Lashley e possíveis aplicações na hotelaria. In: IV Seminário da Associação Brasileira de Pesquisa e PósGraduação em Turismo - ANPTUR, São Paulo, SP, Brasil. Anais..São Paulo, 2007.

Yin, R. K.. Estudo de Caso - Planejamento e Métodos. Porto Alegre: Bookman, 2010. 